\title{
Determinant factor for clearance of ceramic fibres from rat lungs
}

\author{
Hiroshi Yamato, Isamu Tanaka, Toshiaki Higashi, Masamitsu Kido
}

\begin{abstract}
Deposition, clearance, retention, and durability of inhaled particles from lungs are known to be important factors for induction of pulmonary fibrosis or lung cancer. To study the deposition and clearance of alumina silicate ceramic fibres from the lung, male Wistar rats were exposed to ceramic fibre particles with a mass median aerodynamic diameter (MMAD) of $4.2 \mu \mathrm{m}$, for six hours a day, five days a week for two weeks. The average exposure concentration was 20.7 (standard deviation (SD) $4.5) \mathrm{mg} / \mathrm{m}^{3}$. The rats were killed at one day, three months, and six months after the end of exposure, and the fibre numbers and dimensions were measured with a scanning electron microscope. No significant differences in number and geometric mean length of residual ceramic fibres in the lungs were found between the groups. The geometric mean diameter, however, decreased according to the duration of the clearance period. These findings suggest that solubility of fibre contributes most in the clearance of the inhaled ceramic fibres from the lungs.
\end{abstract}

Asbestos has been used in various industrial products because of its physical and chemical properties. It is known, however, that occupational exposure to various types of asbestos causes lung fibrosis (asbestosis), bronchial cancer, and pleural and peritoneal mesotheliomas, and that the use of asbestos fibres has decreased greatly in recent years. On the other hand, because of substitutes for asbestos, and new industrial materials, the global production of manmade mineral fibres (MMMFs) has increased from 4.5 million tonnes in 1973 to six million tonnes in $1985 .{ }^{1}$

Division of Respiratory Disease

H Yamato, M Kido

Department of Environmental Health Engineering I Tanaka

Department of Health Policy and Management, University of Occupational and Environmental Health, Japan

T Higashi
The safety of MMMFs has been questioned because of their similarity in shape and chemical composition to asbestos. Some in vitro and in vivo studies have considered the biological effects of MMMFs and asbestos. $^{2}$

Physical dimension, clearance, and durability of fibres in the lungs were reported as important factors in predicting the biological effect of inhaled fibres. ${ }^{3-6}$ To clarify the durability and size changes of man made ceramic fibres we conducted an inhalation exposure study of ceramic fibres in rats, and determined the changes of numbers, lengths, and diameters of residual ceramic fibres in rat lungs after various clearance times from the end of exposure.

\section{Materials and methods}

TEST SUBSTANCES

Ceramic fibres (alumina silicate refractory fibres with a nominal diameter of $2-3 \mu \mathrm{m}$ ) used in this study were made by one of the largest Japanese manufacturers. The chemical composition of the fibres is $54 \%$ $\mathrm{SiO}_{2}, 46 \% \mathrm{Al}_{2} \mathrm{O}_{3}$. Bulk ceramic fibres were disintegrated three times with an ultracentrifugal mill (Retch Co, Germany) at a speed of $15000 \mathrm{rpm}$ to obtain the materials for exposure.

\section{EXPOSURE SYSTEM AND EXPOSURE CHAMBER}

Figure 1 presents a schematic diagram of the experimental apparatus. The dust generator is the same as that previously reported. ${ }^{78}$ The special feature of the dust generator is the mixing of ceramic fibres with the fluidising particles (small glass beads, diameter $210-297 \mu \mathrm{m}$ and density $2.5 \mathrm{~g} / \mathrm{cm}^{3}$ ) before use. The uniform mixing of the fibres with fluidising particles is important to keep the generation rate of fibrous dust constant. In our experiment, the mixing ratio of the ceramic fibres to the fluidising particles was 0.003 . The ceramic fibres were mixed with the fluidising particles by hand. Two $\mathrm{kg}$ of the fluidising particles were put into a glass bottle and $6 \mathrm{~g}$ of ceramic fibres were added. The bottle was shaken until the colour of the mixture was judged visually to be uniform. The mixing time was about 10 minutes. After mixing, the particles were fed into the hopper and smoothly transported via a continuous screw feeder into the fluidised bed. Dry air passed upwards 


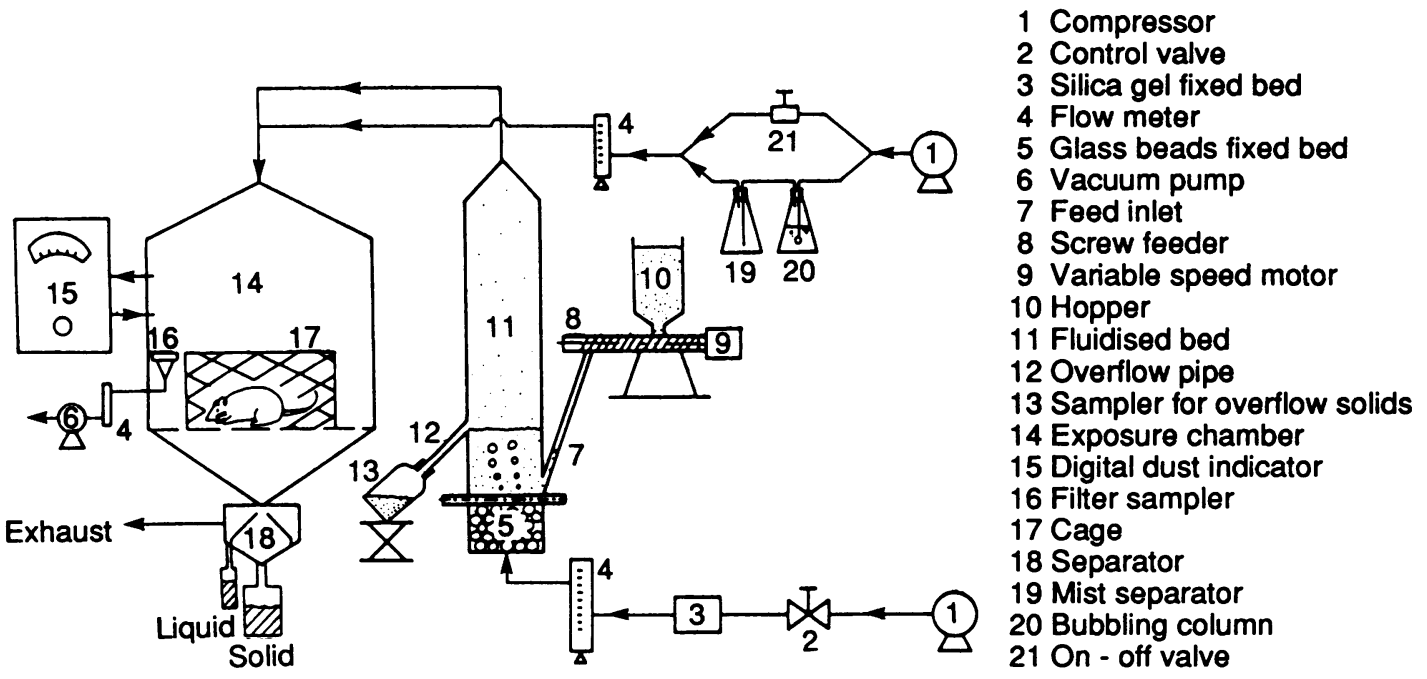

Figure 1 Schematic diagram of exposure chamber.

through the fluidised bed in which the fibrous particles were dispersed. The air velocity was high enough to transport the fibrous particles, but not the fluidising particles, into an exposure chamber (volume $0.48 \mathrm{~m}^{3}$ ). The fluidising particles fell back into the bed and maintained fluidisation until discharged via the overflow pipe.

\section{CONCENTRATION AND SIZE DISTRIBUTION IN THE EXPOSURE CHAMBER}

The mass concentration of ceramic fibres was measured gravimetrically at daily intervals by the isokinetic suction of air through a glass filter. The size distribution of the aerosol in the exposure chamber was determined with an Andersen cascade impactor (air sampler, Andersen type, model AN-200, Sibata Scientific Technology Ltd, Japan). The mass median aerodynamic diameter (MMAD) and the geometric standard deviation (GSD) of the ceramic fibres in the chamber were $4.2 \mu \mathrm{m}$ and 2.0 respectively. Because the sampler is unsuitable for obtaining the full size distribution of fibrous particles, it was only used in this study to check whether the test sample was respirable or not.

\section{RATS}

Male Wistar rats nine weeks old at the start of exposure were used. The rats were exposed to ceramic fibres daily for six hours a day, five days a week, for two weeks and killed at one day, three months, and six months after the end of the exposure. Table 1 summarises the experimental conditions.
Table 1 Experimental conditions for the study

\begin{tabular}{|c|c|}
\hline $\begin{array}{l}\text { Animals } \\
\text { Test material } \\
\text { MMAD } \\
\text { GSD }\end{array}$ & $\begin{array}{l}\text { Male Wistar rats } \\
\text { Alumina silicate ceramic fibre } \\
4 \cdot 2 \mu \mathrm{m} \\
2 \cdot 0\end{array}$ \\
\hline $\begin{array}{l}\text { Exposure: } \\
\text { Exposure period }\end{array}$ & Two weeks ( $6 \mathrm{~h}$ a day, five days a week) \\
\hline $\begin{array}{l}\text { Exposure } \\
\text { concentration } \\
\text { Clearance time }\end{array}$ & $\begin{array}{l}20.7(\mathrm{SD} 4.5) \mathrm{mg} / \mathrm{m}^{3} \\
\text { One day, three months, six months }\end{array}$ \\
\hline
\end{tabular}

* Mass median aerodynamic diameter.

†Geometric standard deviation.

DETERMINATION OF CERAMIC FIBRES IN RAT LUNGS The rats were anaesthetised by intraperitoneal injection of pentobarbital and exsanguinated via the heart at the end of the appropriate experimental period. The lungs were subjected to low temperature ashing $\left(150^{\circ} \mathrm{C}\right)$ in a plasma asher (LAT-2SN Yanaco, Japan) in weighing bottles. The residues were washed in a small amount of $6 \mathrm{~N} \mathrm{HCl}$. After gentle mixing, each sample was diluted to volume and decanted into a nucleopore filter apparatus containing a $0.45 \mu \mathrm{m}$ pore size filter (Toyo Filter, Japan). The weighing bottles were rinsed with distilled water several times with all fluid being passed through the filter.

Numbers, length, and diameter of fibres were determined with a scanning electron microscope (SEM:Hitachi S-700) according to the reference methods for measuring airborne MMMFs proposed by the World Health Organisation. ${ }^{9}$ The filters were cut into squares (roughly $7 \mathrm{~mm} \times 7 \mathrm{~mm}$ ) after 
Table 2 Total number, length, and diameter of inhaled ceramic fibres in rat lungs

\begin{tabular}{lllll}
\hline Clearance time & No of rats & Mean no of fibres $\left(\times 10^{5}\right)(S D)$ & $G M L^{\star}(G S D \dagger)(\mu m)$ & $G M D \ddagger(G S D)(\mu m)$ \\
\hline One day & 4 & $4.9(0.4)$ & $5.4(2.0)$ & $0.88(1.4)$ \\
Three months & 3 & $5 \cdot 6(0.4)$ & $6.0(2.2)$ & $0.78(1.7)$ \\
Six months & 3 & $3.3(1 \cdot 2)$ & $5.5(1.8)$ & $0.56(1.8)$ \\
\hline
\end{tabular}

*Geometric median length.

$\ddagger$ Geometric median diameter.

†eometric standard deviation.

drying, and then put on to scanning electron microscope stubs. They were sputter coated with $7 \mathrm{~nm}$ of platinum and examined by SEM. Photomicrographs of the filters were taken randomly at a fixed magnification $(\times 2000)$. If any of the fibres had only one end within the field of view, a second photomicrograph was recorded at lower magnification and centred on the original fields so that the fibre length could be assessed. The films were printed on $25 \mathrm{~cm} \times 30 \mathrm{~cm}$ photographic papers. The numbers of fibres were counted and the sizes measured on the photographs. Only fibres with an aspect ratio (length:diameter) greater than or equal to $3: 1$ were counted and measured. For the total number of ceramic fibres, we counted one for fibres with two ends in the field and 0.5 for those with one end in the field. The total number of fibres calculated from the fibres and fields was equivalent to the total of deposited fibres in the lungs. The numbers of ceramic fibres were also calculated for each rat. The size distribution of inhaled ceramic fibres was calculated for all rats at each clearance time, and geometric mean length $(G M L)$ and diameter (GMD) were assessed.

\section{Results}

Fibres longer than $50 \mu \mathrm{m}$ were found in the lungs of each group. Recovered fibres had a log normal distribution. Table 2 shows the changes in numbers and dimensions of fibres in the lungs. No significant

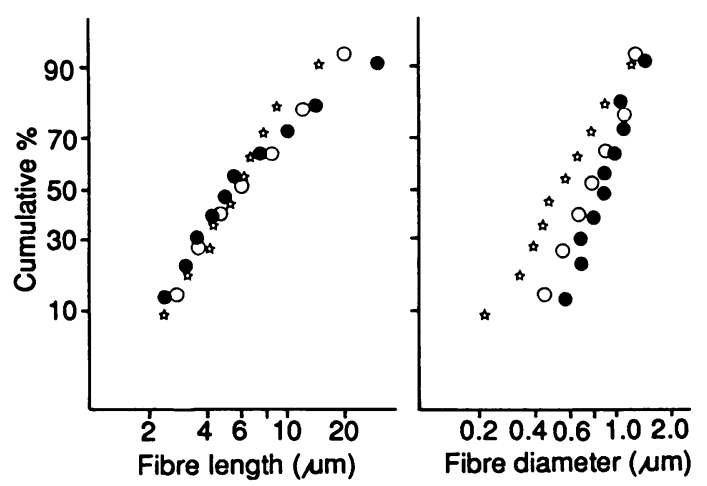

Figure 2 Distribution of fibre length and fibre diameter after one day ( ), three months (O), and six months (i) clearance time. difference was found between each clearance period in terms of the residual numbers of inhaled ceramic fibres. There was also no significant difference in the GML between each clearance period. The GMD decreased, however, according to the duration of the clearance time (figs 2 and 3 ).

\section{Discussion}

Previous reports ${ }^{2-6}$ suggested the following clearance mechanisms of inhaled particles from lungs: mucociliary transport, translocation to lymph nodes by alveolar macrophages, and dissolution by extracellular fluid.

Bernstein $e t \mathrm{al}^{2}$ examined the clearance of radioactive glass fibres that had known size distribution (GMD $1.5 \mu \mathrm{m}$, length of either 5 or $60 \mu \mathrm{m}$ ) from the lungs of Fisher 344 rats. There was little difference in clearance between long (half life 35.0 days) and short (half life 38.5 days) fibres at 19 weeks after instillation, but the short fibres were apparently successfully phagocytised by alveolar macrophages and cleared to the lymph nodes whereas the long fibres were not. The long fibres also produced a granulomatous response in giant cells.

Morgan et $^{3}$ l $^{3}$ reported that $5 \times 1.5 \mu \mathrm{m}$ fibres were $90 \%$ cleared and $10 \times 1.5 \mu \mathrm{m}$ fibres were $80 \%$ cleared from lungs during the 12 months after administration. Neither $30 \times 1.5$ nor the $60 \times 1.5 \mu \mathrm{m}$ fibres were cleared to any significant extent over the 12 month period. They also showed that the count median diameter (CMD) of $10 \times 1.5 \mu \mathrm{m}$ fibres was reduced by $28 \%$. The

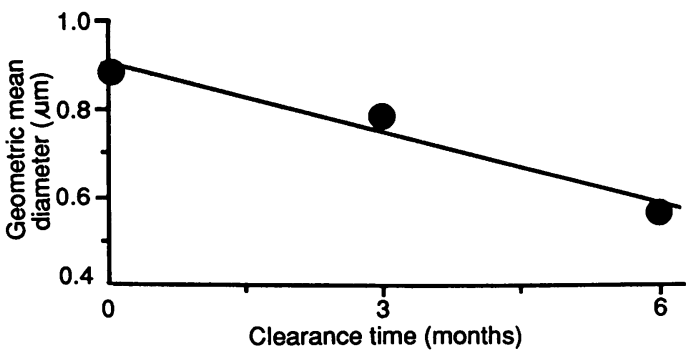

Figure 3 Decrease of geometric mean diameter of ceramic fibres with clearance time. 
$30 \times 1.5$ and $60 \times 1.5 \mu \mathrm{m}$ fibres dissolved much more rapidly and the CMD of the residual populations after 18 months was less than half that of the original. Their study concluded that longer fibres were more soluble than shorter ones.

Abraham et $a l^{5}$ conducted inhalation exposure experiments with chrysotile or crocidolite asbestos that had similar size distributions. After 90 days, $95 \%$ of the chrysotile fibre was cleared but no measurable clearance of crocidolite was seen. A decrease in mass was shown by $x$ ray diffraction and could be calculated from changes in fibre dimensions. The chrysotile that was retained appeared to be the longer, thinner, fibres. This type of selective clearance was not found with crocidolite.

Morgan and $\mathrm{Holmes}^{4}$ found no significant change in the GMD of instilled rockwool fibres in rat lungs. Even after six months, it was apparent that the fibres became thinner at their ends than in the middle, and that slow dissolution occurred. Leineweber ${ }^{6}$ has shown that the solubility of MMMFs in vitro varied over a wide range and depended on their composition.

Timbrell ${ }^{10}$ compared the length distribution of anthophyllite fibres in the lungs of Finnish workers with that of fibres that had been airborne, and concluded that the critical length above which fibres could not be cleared from the lung was about $17 \mu \mathrm{m}$. The studies mentioned indicate that many mechanisms can be used to eliminate inhaled fibres.

The present study showed that the critical factor for clearance of ceramic fibres is the decrease in fibre diameter, and that it depends on the solubility of the fibre. According to the Stanton-Pott hypothesis, the fibres longer than $8 \mu \mathrm{m}$ and thinner than $0.25 \mu \mathrm{m}$ have high carcinogenicity. Our study suggested that even the original diameters of inhaled ceramic fibres are thicker than Stanton fibres, and could be the size of Stanton fibres in the process of clearance time. The relation between the findings in the present study and the biological effects of MMMFs will be considered in future studies.

Requests for reprints to: Hiroshi Yamato $M D$, Division of Respiratory Disease, University of Occupational and Environmental Health, Japan, 1-1 Iseigaoka, Kitakyushu, 807 Japan.

1 Tanaka I, Akiyama T. Pulmonary deposition fraction of a glass fiber in rats by inhalation. In: Masuda $S$, Takahashi $\mathrm{K}$, eds. Aerosols-science, industry, health and environment. Oxford: Pergamon Press, 1990;1242-5.

2 Bernstein DM, Drew RT, Kuschner M. Experimental approaches for exposure to sized glass fibers. Environ Health Perspect 1980;34:47-57.

3 Morgan A, Holmes A, Davison W. Clearance of sized glass fibres from the rat lung and their solubility in vivo. Ann Occup $H y g$ 1982;25:317-31.

4 Morgan A, Holmes A. Solubility of rockwool fibres in vivo and the formation of pseudo-asbestos bodies. Ann Occup Hyg 1984;28:307-14.

5 Abraham JL, Smith CM, Mossman B. Chrysotile and crocidolite asbestos pulmonary fiber concentrations and dimensions after inhalation and clearance in Fischer 344 rats. Ann Occup Hyg 1988;32:203-11.

6 Leineweber JP. Solubility of fibres in vitro and in vivo. In: Proceedings of World Health Organisation/International Agency for Research on Cancer conference. Biological effects of man-made mineral fibres. Copenhagen: WHO 1984;87-101.

7 Tanaka I, Akiyama T. Fibrous particles generator for inhalation toxicity studies. Ann Occup Hyg 1987;31:401-3.

8 Tanaka I, Akiyama T. A new dust generator for inhalation toxicity studies. Ann Occup Hyg 1984;28:157-62.

9 Reference methods for measuring airborne man-made mineral fibres (MMMF). Copenhagen: Regional Office for Europe World Health Organisation. 1985:36-54. (P999A PB Rep (USA).)

10 Timbrell V. Deposition and retention of fibres in the human lung. Ann Occup Hyg 1982;26:347-69.

Accepted 22 July 1991 